\title{
ANÁLISE DO USO DE UM JOGO PARA EDUCAÇÃO EM SAÚDE COM ADOLESCENTES
}

\author{
ANALYSIS OF THE USE OF A GAME FOR HEALTH EDUCATION WITH \\ TEENAGERS \\ Claudilene Moura Perim ${ }^{1}$, Taís Rabetti Giannella ${ }^{2}$, Miriam Struchiner ${ }^{3}$ \\ ${ }^{1}$ Universidade Federal do Rio de Janeiro/ Núcleo de Tecnologia Educacional para a Saúde (NUTES), \\ lena.perim@uol.com.br \\ ${ }^{2}$ Universidade Federal do Rio de Janeiro/ Núcleo de Tecnologia Educacional para a Saúde (NUTES), \\ taisrg@yahoo.com.br \\ ${ }^{3}$ Universidade Federal do Rio de Janeiro/ Núcleo de Tecnologia Educacional para a Saúde (NUTES), \\ miriamstru@gmail.com
}

\section{RESUMO}

O objetivo deste estudo foi analisar a percepção de um grupo de alunos e professores de uma escola municipal do Rio de Janeiro sobre o uso de um jogo para adolescentes mediado por Tecnologias Digitais de Informação e Comunicação (TDIC) como estratégia pedagógica para mobilizar os conteúdos de saúde. Participaram dessa pesquisa dois professores (Ciências e Matemática), a Coordenadora Pedagógica e 37 alunos de uma turma do $9^{\circ}$ ano. Os resultados indicaram uma avaliação positiva, porém com alguns desafios técnicos relacionados ao uso da TDIC. O caráter lúdico da atividade proporcionou um ambiente favorável para discussão de temáticas complexas para esse público. Além disso, o uso de TDIC potencializou a dinâmica do jogo, favorecendo a pesquisa e análise crítica de informações e a colaboração entre os alunos.

Palavras-chave: Jogo, Educação em Saúde, Adolescente, TDIC

\begin{abstract}
This study aimed to analyze the perception of a group of students and teachers at a public school in Rio de Janeiro on the use of a game for teenagers mediated by Information and Communication Technologies (ICT) as a pedagogical strategy for mobilizing content health. Participated in this study: two teachers (Science and Mathematics), the Pedagogical Coordinator and 37 students in a class in 9th grade. The results indicated a positive evaluation, but with some technical challenges related to the use of ICTs. The playful nature of the activity provided a favorable environment for discussion of complex issues to the public. Furthermore, the use of ICT enhanced the dynamics of the game, favoring research and critical analysis of information and collaboration among students.
\end{abstract}

Key words: Game, Health Education, Teenager, ICT

\section{INTRODUÇÃO}

Proporcionar condições aos adolescentes para apropriação crítica de conhecimentos sobre saúde, cujas reflexões e discussões repercutam em suas vidas em 
sociedade, desafia a escola a introduzir estratégias pedagógicas que incorporem linguagens e práticas relacionadas ao cotidiano dessa população, de modo a tornar este processo participativo e prazeroso (IERVOLINO, 2000).

$\mathrm{Na}$ abordagem de temas relacionados à saúde, a escola enfrenta diversos desafios, tais como a escassez de conteúdos e materiais de apoio e a formação inadequada de professores (MONTEIRO, 2012). Estes fatores, associados ao hiato existente entre os conteúdos abordados e a realidade social dos adolescentes, refletem na falta de interesse por parte destes jovens na participação nas atividades educativas propostas pelos professores. Portanto, torna-se necessário buscar novas práticas pedagógicas que aproximem a escola do cotidiano dos alunos, favorecendo a construção de um conceito ampliado de saúde e motivando sua participação ativa no processo de construção desse conhecimento.

Neste sentido, Yonekura e Soares (2010) apontam o jogo educativo como uma alternativa viável para facilitar a discussão de temas relevantes sobre saúde, como diabetes, infecções respiratórias infantis, cuidados no puerpério, e até mesmo temas mais sensíveis como drogas e AIDS, podendo ser utilizados em diversas situações, envolvendo crianças, adolescentes e adultos. Falta algo para caracterizar a opinião desses autores sobre o uso dos jogos educativos.

$\mathrm{Na}$ discussão sobre a necessária transformação das práticas pedagógicas, as Tecnologias Digitais de Informação e Comunicação (TDIC) têm sido situadas como importantes ferramentas de inovação. Estas estão cada vez mais presentes no cotidiano da nossa sociedade, sendo parte integrante da vida de vários jovens. Assim, torna-se necessário refletir sobre a sua utilização no ambiente educacional e como o aluno se apropria desta tecnologia no seu processo de aprendizagem (MATTAR, 2010).

Com base nestas questões e com o objetivo de analisar as potencialidades pedagógicas do uso de jogos mediados por TDIC, um jogo de tabuleiro que contempla temas relacionados à saúde do adolescente foi adaptado e alguns de seus elementos foram digitalizados para ser utilizado no ambiente escolar.

Este trabalho apresenta uma experiência de utilização do jogo Saúde do Adolescente no âmbito do projeto "Análise do processo de integração de tecnologias de informação e comunicação em atividades no ensino fundamental" no contexto do 
Programa um Computador por Aluno (PROUCA) (STRUCHINER, 2011). Tem como objetivo analisar a perspectiva de alunos e professores sobre a utilização deste jogo, de arquitetura mista (jogo físico e digital), como estratégia para abordar os conteúdos de saúde no contexto de práticas educativas informatizadas em uma escola municipal do Rio de Janeiro, RJ.

Essa pesquisa fundamenta-se em conceitos de Educação em Saúde e da utilização de jogos mediados pelo uso das TDIC no processo de ensino-aprendizagem (MAINARDI, 2010; MATTAR, 2010 p.29-31).

\section{REFERENCIAL TEÓRICO}

Adolescentes passam grande parte do seu tempo na escola, ocupando um espaço privilegiado para desenvolver práticas educativas em saúde. Lidar com esse segmento da população é um desafio, pois a adolescência é uma fase marcada por intensas mudanças de ordem física, psicológica e sociocultural. O adolescente vivencia essas mudanças e enfrenta processos conflituosos que, muitas vezes, não ganham uma escuta sensível, nem por parte da família, nem por profissionais da área da saúde e da educação (BRASIL, 2009)

Carvalho, Fonseca e Pedrosa (2004) afirmam que a educação é um dos meios para vencer os desafios impostos pela sociedade, propiciando o aprendizado de novos conhecimentos a fim de despertar a consciência crítica para a busca de uma vida melhor.

Ao aproximar o jogo do contexto da educação, Wideman et al (2007, p.13) ressaltam que seu uso potencializa a compreensão de conceitos complexos "sem perder as conexões entre os problemas reais e as ideias abstratas que podem ser usadas para resolvê-los". De acordo com Huizinga (1993, p16), “O jogo é uma atividade voluntária realizada dentro de alguns limites de tempo e espaço, através de regras livremente consentidas, porém obrigatórias, dotadas de um fim em si mesmo, guiadas por sentimentos de tensão e alegria e de uma consciência, de ser diferente da vida cotidiana". 


\section{Ensino, Saúde e Ambiente - V 7 (1), Edição Especial, maio de 2014}

Nos dias atuais, grande parte dos adolescentes utiliza diariamente o computador para entretenimento, sendo os jogos uma das formas mais populares entre eles. Assim, esta familiaridade pode ser utilizada a favor do processo educativo.

O desenvolvimento de estratégias de ensino-aprendizagem baseadas no uso de jogos mediados por TDIC apoiam-se no paradigma construtivista do conhecimento. Em seus estudos, Vygotsky (1988) constatou que a brincadeira cria "zonas de desenvolvimento proximal" (ZDP), uma vez que a criança pode ir além do comportamento habitual da sua idade. O jogo pode ser utilizado em situações de interação entre educando-educando e educando-educador. Portanto, a brincadeira é uma situação privilegiada de aprendizagem na qual o desenvolvimento pode alcançar níveis mais complexos, exatamente pela possibilidade de interação entre os pares e entre crianças e adultos e pela negociação de regras de convivência e de conteúdos temáticos. As brincadeiras, em geral, são permeadas pelo uso de brinquedos e jogos, que representam os objetos originais, possibilitando à criança manipulá-los e testá-los, levando a apropriação dos mesmos e da realidade que representam. Vygotsky argumenta que a atividade criadora da imaginação depende diretamente da riqueza e diversidade da experiência anterior do sujeito, já que esta influencia o material com o qual se estrutura a fantasia. Quanto mais rica a vivência do sujeito, maior a bagagem com que contará sua imaginação, uma vez que, segundo o autor, o jogo simula a realidade e é imitação, imaginação e criação.

O uso de jogos no contexto escolar ainda suscita questionamentos, já que algumas pessoas acreditam que haja uma contradição na sua aplicação como estratégia pedagógica. Isto, porque, a educação é vista, muitas vezes, como uma atividade séria e controlada, enquanto jogar lembra diversão ou simplesmente brincadeira. No entanto, a liberdade e a ludicidade características dos jogos podem ser conciliadas com a natureza didática do processo de ensino-aprendizagem escolar (CUNHA, 2012). O uso de jogos educativos pode integrar a aprendizagem de conteúdos/conceitos científicos com o desenvolvimento de atitudes e valores, mantendo o equilíbrio lúdico-educativo apontado por Kishimoto (2003).

Para Schall et al (1999), o jogo é capaz de contribuir tanto para o desenvolvimento da educação, quanto para a construção do conhecimento em saúde. Ao proporcionarem interação entre participantes, estimulam o interesse e oferecem espaço 
para a discussão de temas polêmicos, complexos e atuais, difíceis de serem tratados em situações educativas tradicionais. Se por um lado, o jogo auxilia o estudante a construir conhecimentos e valores sobre os desafios e questões apresentados, desenvolvendo e enriquecendo sua personalidade, por outro, situa o professor na condição de mediador, estimulador e avaliador da aprendizagem (CUNHA, 2012, p. 92).

Com base nestes conceitos, o presente estudo ancora-se em três premissas básicas: (1) a escola é um locus importante de produção de conhecimento sobre saúde (2) A tecnologia é um importante componente do modo de vida atual - principalmente dos jovens e (3) o jogo educativo constitui-se em uma estratégia pedagógica adequada à abordagem da temática da saúde com adolescentes. Considerando tais perspectivas, descreve-se, a seguir, a metodologia.

\section{METODOLOGIA}

Trata-se de um estudo exploratório de base qualitativa que analisa a percepção dos sujeitos envolvidos, professores e alunos, sobre a utilização de um jogo para adolescentes que tem como objetivo mobilizar diferentes conteúdos de saúde: sexualidade, drogas, DST/HIV/AIDS, gravidez e meios de prevenção, alimentação, cidadania e bullying. Para Silva e Menezes (2000, p.21), este tipo de pesquisa pressupõe a coleta de dados a partir de observação, entrevistas, grupos focais, entre outros.

\section{CONTEXTO E SUJEITOS DO ESTUDO}

A definição do campo de estudo teve como base o projeto "Com-viver, ComCiência e Cidadania", que consistiu na realização de atividades, relacionadas à temática da saúde, integradas aos conteúdos de todas as disciplinas, ao longo de uma semana em uma turma do $9^{\circ}$ ano de uma escola municipal do Rio de Janeiro. O objetivo do projeto foi construir, com professores e alunos, a compreensão de que ter uma vida saudável é mais do que ter um corpo saudável e que, portanto, saúde é um tema amplo, complexo e interdisciplinar. Participaram da aplicação do jogo em sala de aula e do estudo, as professoras de Ciências e Matemática, a Coordenadora pedagógica e os 37 alunos do $9^{\circ}$ da turma 1901. 


\section{MATERIAIS}

A primeira versão do "Jogo Saúde do Adolescente" foi desenvolvida no âmbito do Programa Saúde na Escola (Secretaria Municipal de Saúde) e aplicada em uma escola do Rio de Janeiro. Na presente pesquisa, alguns recursos foram adaptados para integrar o uso do computador e estimular os alunos a pesquisarem durante o jogo. Tratase de um jogo do tipo trilha, composto por um tabuleiro de $1,50 \mathrm{~m} \times 1,50 \mathrm{~m}$, cinco cones coloridos, um dado, 50 cartas online com perguntas/respostas e um livreto de regras. Cada aluno tinha um computador portátil disponível para pesquisar as respostas das questões propostas na Internet.

\section{COLETA E TRATAMENTO DOS DADOS}

As informações foram coletadas por meio de observação participante, de entrevistas (gravadas) com professores e de uma sessão de discussão com alunos ocorrida no último dia das práticas educativas desenvolvidas ao longo da semana. Elaborou-se um roteiro orientador para auxiliar a coleta, o registro e a análise de dados. Para avaliar a opinião dos alunos sobre a atividade, foi elaborado um questionário, respondido ao final da atividade.

A análise dos dados buscou identificar a percepção dos sujeitos quanto à utilização do jogo com temas relacionados à saúde de adolescentes, às mudanças no conhecimento sobre saúde por parte dos adolescentes, ao uso de TDICs permeando as atividades do jogo, além de aspectos relacionados à motivação e ao engajamento dos participantes nas atividades propostas. Para sintetizar os dados, as falas dos sujeitos foram organizadas em relação às referências gerais trazidas pelos participantes, às suas percepções sobre os aspectos positivos e negativos (funcionaram ou não), sobre a abordagem do tema saúde e sobre suas principais sugestões.

\section{RESULTADOS E DISCUSSÃO}

A análise dos dados e da observação apontou, em geral, para uma avaliação positiva dos participantes em relação ao uso do jogo para a construção de 
conhecimentos em Saúde pelos adolescentes. O rompimento da rotina da escola e o uso do computador durante as atividades marcaram as falas de educadores e alunos. $\mathrm{O}$ tempo dedicado às atividades foi considerado suficiente pela maioria dos pesquisados. Na pesquisa de opinião dos alunos sobre o jogo, a atividade foi classificada como "boa" ou "ótima" por 95\% dos alunos e o mesmo percentual considerou que o jogo ajudaria no processo de construção de conhecimento em sala de aula. Para 80\% dos alunos, o jogo despertou o interesse para assuntos relacionados com Saúde. Saúde bucal e alimentação saudável surgiram como sugestões de temas a serem incluídos no jogo.

Os aspectos marcantes da experiência encontram-se na síntese das observações dos pesquisadores sobre a dinâmica da atividade com o jogo em sala de aula, seguir: (1) inicialmente, as regras não estavam bem entendidas pelos alunos, demandando mais tempo para organizar a turma e iniciar a atividade; (2) o ritmo do jogo precisou ser dosado para permitir o aprofundamento na discussão das dúvidas e temas das perguntas; (3) não houve interferência na formação dos grupos de alunos para o jogo; os alunos se agruparam de acordo com suas afinidades; (4) não foi observado nenhum tipo de segregação entre meninos e meninas: a maioria se organizou em grupos mistos; (5) a maioria dos alunos participou ativamente das atividades, mas houve alguns que dispersaram quando não era sua vez de jogar; (6) em geral, o clima de competição funcionou como fator de motivação, mas para alguns alunos a competição era o foco da atividade; (7) houve bastante interação e participação por parte dos alunos; (8) muitos alunos utilizaram o jogo para tirar dúvidas sobre os temas abordados pelo jogo (sexualidade, gravidez na adolescência, bullying); (9) clima muito positivo durante a atividade; ao final, os alunos pediram para repetir a atividade.As sínteses das percepções de professores e alunos, objeto do presente estudo, são apresentadas nas Tabelas 1 e 2.

Cunha (2012) afirma que a inclusão do jogo no planejamento pedagógico do professor tem papel fundamental para a manutenção do equilíbrio entre a função lúdica e a pedagógica da atividade. Apesar de a maioria dos professores terem considerado satisfatórios o planejamento e a execução das atividades durante a semana, alguns reconheceram que o maior envolvimento docente no planejamento contribuiria na obtenção de melhores resultados. Ainda com relação ao planejamento, os educadores sugeriram que esta atividade deveria fazer parte do planejamento anual da instituição, além da necessidade da "integração entre os professores das diversas matérias" na sua 
preparação, reforçando o potencial do jogo para uma abordagem interdisciplinar do tema saúde.

Falas sobre o uso computador e da Internet durante as atividades foram recorrentes nos dados coletados. Tarouco et al (2004, p. 1) afirma que o uso do computador proporciona ao professor a oportunidade de enriquecer sua prática pedagógica com recursos que possibilitam ao aluno aprender de forma divertida e motivadora. A autora ressalta que uso de recursos tecnológicos deve sempre estar fundamentado e atrelado a princípios teórico-metodológicos claros, sendo de grande importância que os professores dominem as tecnologias e avaliem criteriosamente os recursos a serem utilizados, tendo em vista os objetivos educacionais. Os professores entrevistados reconheceram que foram estimulados a desenvolver suas habilidades e familiaridade com a tecnologia e com os conteúdos por ela disponibilizados. Já os alunos, disseram sentirem-se motivados a usar seus computadores na busca objetiva de informações e respostas aos desafios que lhes foram colocados. Ambos os grupos professores e alunos - mencionaram a instabilidade do acesso à Internet disponibilizado (lentidão e falta de conexão) como fator negativo para o evento.

Para Kishimoto (2003), o conceito de jogo educativo está ligado à possibilidade de aprendizagem e de respeito à natureza lúdica do ato de jogar. Neste estudo, estes dois elementos foram marcantes nas falas dos alunos, quando mencionam que aprenderam se divertindo, que o jogo "quebrou rotina" e "não foi uma aula chata" e que "aprendemos coisas que achávamos que já sabíamos".

Os educadores entrevistados enfatizaram o caráter motivador e mobilizador do jogo na turma e reconheceram que o ambiente de competição com descontração estimulou tanto o espírito de equipe como a participação individual na atividade. A temática saúde de adolescentes despertou grande interesse dos alunos que sentiram-se à vontade para esclarecer suas dúvidas e expor abertamente seus pontos de vista. O estimulo à interação e à discussão aberta de temas mais polêmicos para os adolescentes é um dos diferenciais apresentados por Shall, Monteiro, Rebello e Torres (1999) para utilização do jogo na construção de conhecimento em saúde. Como resultado, dentre os temas abordados durante o jogo, foram selecionados e divulgados em um jornal escolar aqueles que mais geraram discussões e participação dos alunos. Os educadores também 
reconheceram a possibilidade da utilização do jogo na abordagem de outros temas além da saúde (diversidade sexual e meio ambiente foram citados).

Os pesquisadores observaram a importância de comunicar os objetivos e as regras do jogo claramente e anteriormente ao seu início, de modo a evitar que o foco por parte dos alunos fique no jogo em si ao invés de na aprendizagem. Outro aspecto observado está relacionado ao ritmo com que é conduzido o jogo, que deve ser dosado de modo a permitir o aprofundamento nas discussões dos temas levantados pelas perguntas. Os fatos notados pelos pesquisadores reforçam os aspectos citados por Cunha (2000) quanto à importância do educador como orientador das atividades, para manter o equilíbrio entre o pedagógico e o lúdico, evitando que o jogo se transforme em uma simples brincadeira em sala de aula.

Tabela 1 - Síntese da percepção dos Professores

\begin{tabular}{|c|c|}
\hline Tópico & Comentários \\
\hline $\begin{array}{l}\text { Referências ao } \\
\text { jogo }\end{array}$ & $\begin{array}{l}\text { “Jogo foi ótimo” } \\
\text { "Jogo foi bem organizado” } \\
\text { “Possibilita trabalhar outros conteúdos além da Saúde” } \\
\text { "Quebrou a rotina” } \\
\text { "Tive que me familiarizar mais com as ferramentas disponibilizadas } \\
\text { pelo computador” }\end{array}$ \\
\hline O que funcionou? & $\begin{array}{l}\text { Feedback positivo dado pelos alunos } \\
\text { Serviu para a mobilização de alunos } \\
\text { Quebra da rotina da escola } \\
\text { Tempo adequado para as atividades } \\
\text { Trabalho em grupo } \\
\text { Uso do computador durante as atividades } \\
\text { Competição como fator de motivação para os alunos } \\
\text { Interação entre alunos } \\
\text { Oportunidade para os alunos lidarem lidar com diversidade de } \\
\text { Exposição do professor a novas ferramentas pedagógicas }\end{array}$ \\
\hline $\begin{array}{l}\text { O que não } \\
\text { funcionou? }\end{array}$ & $\begin{array}{l}\text { Tempo insuficiente para as atividades } \\
\text { Participação limitada dos professores no planejamento } \\
\text { Indisponibilidades frequentes de acesso à internet } \\
\text { Necessidade de planejamento prévio para a inclusão deste tipo de } \\
\text { atividade no currículo do professor }\end{array}$ \\
\hline $\begin{array}{l}\text { Comentários } \\
\text { sobre a } \\
\text { abordagem do } \\
\text { tema saúde }\end{array}$ & $\begin{array}{l}\text { Professor participar no planejamento } \\
\text { Falta de integração entre os professores das diversas matérias } \\
\text { Trabalhar outros temas (integração racial, questões sociais) } \\
\text { Este tipo de atividade deve ser incluída o planejamento anual da }\end{array}$ \\
\hline Sugestões & $\begin{array}{l}\text { Incluir a saúde como eixo para abordar outros temas dentro de } \\
\text { cada disciplina (fatores sociais e ambientais) } \\
\text { Ampliar o entendimento de saúde abordando o tema através de } \\
\text { várias disciplinas (matemática, educação física, geografia) } \\
\text { Ter um produto tangível ao final da atividade }\end{array}$ \\
\hline
\end{tabular}

Edição Especial com os melhores trabalhos apresentados no IV ENECiências: UFF - 13 a 16 de maio de 2014. 
Tabela 2 - Síntese da percepção dos Alunos

\begin{tabular}{|l|l|}
\hline Tópico & Comentários \\
\hline Referências ao jogo & $\begin{array}{l}\text { “O jogo quebrou a rotina. Não foi uma aula chata” } \\
\text { “Aprender se divertindo” } \\
\text { “Aprendemos coisas que achávamos que já sabíamos” }\end{array}$ \\
\hline O que funcionou? & $\begin{array}{l}\text { Uso do computador para pesquisar as respostas } \\
\text { Um assunto (bullying) puxando discussões sobre vários } \\
\text { Estimulou o trabalho em grupo }\end{array}$ \\
\hline $\begin{array}{l}\text { O que não } \\
\text { funcionou? }\end{array}$ & $\begin{array}{l}\text { Enquanto um grupo jogava, outros não prestavam atenção } \\
\text { (dispersão de alguns alunos durante a atividade). }\end{array}$ \\
\hline $\begin{array}{l}\text { Comentários sobre a } \\
\text { saúde }\end{array}$ & $\begin{array}{l}\text { Discussão de temas difíceis de conversar e que não se } \\
\text { conhece bem do tema }\end{array}$ \\
\hline Sugestões & Repetir este tipo de atividade \\
\hline
\end{tabular}

\section{CONSIDERAÇÕES FINAIS}

No ambiente escolar, o planejamento tem papel fundamental para que o jogo alcance resultados efetivos de construção de conhecimento por parte dos alunos. O jogo deve ser parte do planejamento pedagógico do professor e da instituição e sua utilização deve ser precedida de uma criteriosa preparação. Além disto, analisar e entender o contexto social em que a escola e seus alunos estão inseridos, levando seus conflitos e limitações para a dinâmica do jogo, é fundamental para que este atinja seus objetivos e torne-se uma ferramenta de transformação.

Os depoimentos de professores e dos alunos deste estudo reforçam que o jogo, por suas características motivadoras, quando utilizado de forma adequada, pode contribuir efetivamente para a construção de conhecimento em temas como saúde em uma perspectiva abrangente e complexa, criando um ambiente que estimula a participação ativa e dá voz aos alunos. Segundo estes depoimentos, as atividades propostas proporcionaram o debate aberto, a participação individual e o trabalho em grupo.

A inclusão das TDICs aportou motivação adicional a professores e alunos, mas também trouxe alguns desafios. Sem o pleno domínio das ferramentas disponibilizadas pela tecnologia por parte dos professores, coloca-se em risco sua efetividade. Os alunos, por sua vez, mostraram deselvoltura no uso da tecnologia. A combinação entre jogo 
físico e internet trouxe dinâmica, diversidade e movimentação na atividade. Os suportes para uso das TDIC, tais como equipamentos e acesso à Internet, por sua vez, precisam estar disponíveis e com um desempenho adequado para as atividades propostas, sob risco de causarem desapontamento e frustração se falharem com frequência.

As percepções dos professores quanto à inclusão do jogo no planejamento pedagógico da instituição, merece atenção nesta discussão. O planejamento mais sistemático desta atividade permitiria, além do alinhamento dos conteúdos com as disciplinas e dos materiais educativos com a realidade dos alunos, a identificação antecipada das necessidades de infraestrutura de tecnologia e do desenvolvimento de novas habilidades pelos educadores. Um modelo de referência para o planejamento da inclusão de jogos educativos para a educação em saúde mediados por TDIC, com base nos resultados do presente estudo, será objeto de futuras pesquisas.

\section{REFERÊNCIAS}

BRASIL. Ministério da Saúde. Secretaria de Atenção à Saúde. Departamento de Atenção Básica. Saúde na escola / Ministério da Saúde, Secretaria de Atenção à Saúde, Departamento de Atenção Básica. - Brasília: Ministério da Saúde, 2009. 96 p.: il. (Série B. Textos Básicos de Saúde) (Cadernos de Atenção Básica; n. 24)

CARVALHO, C.; FONSECA, C.; PEDROSA, J. Heath education on osteoporosis for elderly university students. Cadernos de Saúde Pública, v. 20, n. 3, p. 719-726, 2004. Disponível em http://www.scielosp.org/scielo.php?script= sci_arttext\&pid=S0102311X2004000300008>. Acesso em 23 de Fevereiro de 2013.

CUNHA, M. Jogos Didáticos de Química. Santa Maria: Grafos, 2000.

. Jogos no ensino de química: considerações teóricas para sua utilização

em sala de aula. QUÍMICA NOVA NA ESCOLA. v. 34, n. 2, p. 92-98, Maio 2012. Disponível em <http://www.qnesc.sbq.org.br/online/qnesc34_2/07-PE-53-11.pdf>. Acesso em 13 de Março de 2013.

GIL, A.C. Métodos e técnicas de pesquisa social. São Paulo: Atlas, 1987.

HUIZINGA, D. Homo Ludens: o jogo como elemento da cultura. 4. ed. Tradução João Paulo Monteiro. São Paulo: Perspectiva, 1993.

IERVOLINO, S. Escola promotora da saúde: um projeto de qualidade de vida. 2000. Dissertação (Mestrado em Serviços de Saúde Pública) - Faculdade de Saúde Pública, Universidade de São Paulo, São Paulo, 2000. Disponível em:

$<$ http://www.teses.usp.br/teses/disponiveis/6/6135/tde-01072006-211720/>. Acesso em: 2013-08-10.

KISHIMOTO, T. (org). Jogo, brinquedo, brincadeiras e a educação. 7. ed. Cortez: São Paulo, 2003. 
MAINARDI, N. Educação em saúde: problema ou solução? 2010. Tese (Doutorado em Serviços de Saúde Pública) - Faculdade de Saúde Pública, Universidade de São Paulo, São Paulo, 2010. Disponível em: <http://www.teses.usp.br/teses/ disponiveis/6/6135/tde-13042010-165902/>. Acesso em: 2013-08-10.

MATTAR, J. Games em Educação. Como os nativos digitais aprendem. Pearson Prentice Hall: São Paulo, 2010.

MOHR, A. A saúde na escola: análise de livros didáticos de $1^{\mathrm{a}}$ a $4^{\mathrm{a}}$ séries. Cadernos de Pesquisa, n.94, p.50-57, 1995. Disponível em < http://educa.fcc.org.br/scielo.php? script $=$ sci $\_d f \& p i d=S 0100-15741995000300006 \& \operatorname{lng}=$ pt\&nrm $=$ iso $\&$ tlng $=$ pt $>$. Acesso em 23 de Fevereiro de 2013.

Análise do conteúdo de 'saúde' em livros didáticos. Ciência \& Educação, v. 6, n. 2, p. 89-106, 2000. Disponível em < www.scielo.br/pdf/ciedu/v6n2/02.pdf $>$. Acesso em 23 de Fevereiro de 2013.

MONTEIRO, P. A saúde nos livros didáticos no Brasil: concepções e tendências nos anos inicias do ensino fundamental. 2012. Tese (Doutorado em Educação) - Faculdade de Educação, Universidade de São Paulo, São Paulo, 2012. Disponível em: $<\mathrm{http}$ //www.teses.usp.br/teses/disponiveis/48/48134/tde-04072012-131023/>. Acesso em: 2012-11-20.

SCHALL, V. et al. Evaluation of the ZIG-ZAIDS game: an entertaining educational tool for HIV/Aids prevention. Cadernos de Saúde Pública, v. 15, p. S107-S119, 1999. Disponível em <www.scielo.br/pdf/csp/v15s2/1292.pdf >. Acesso em 3 de Março de 2013.

SILVA, E.; MENEZES, E. Metodologia da pesquisa e elaboração de dissertação. 3 ed. Rev. Atual. Florianópolis: Laboratório de Ensino à Distância da UFSC, 2001. Disponível em $<$ http://tccbiblio.paginas.ufsc.br/files/2010/09/024_Metodologia _de_pesquisa_e_elaboracao_de_teses_e_dis sertacoes1.pdf $>$. Acesso em 30 de Março de 2013.

STRUCHINER, M. Análise do Processo de Integração de Tecnologiasde Informação e Comunicação em Atividades Educativas no Ensino Fundamental no Contexto do "Programa Um Computador por Aluno" (PROUCA). Projeto. (2011)

TAROUCO, L. et al. Jogos educacionais. Novas Tecnologias. CINTED-UFRGS na Educação, v. 2, n. 1, p. 1-7, 2004.

VYGOTSKY, L. A Formação Social da Mente. O Desenvolvimento dos Processos Psicológicos Superiores. 2. Ed. Ed. Martins Fonte, São Paulo, 1998.

WIDEMAN, H. et al. Unpacking the potential of educational gaming: a new tool for gaming research. Simulation \& Gaming, Thousand Oaks, v. 38, n. 1, p. 10-30, 2007. Disponível em $<$ http://www.yorku.ca/ rowston/unpacking.pdf $>$. Acesso em $21 \mathrm{de}$ março de 2013

YONEKURA, T.; SOARES, C. O jogo educativo como estratégia de sensibilização para coleta de dados com adolescentes. Rev. Latino-Am. Enfermagem, Ribeirão Preto, v. 18, n. 5, Oct. 2010. Disponível em $<$ http://wwwscielo.br/scielo.php? script=sci arttext\&pid=S0104-11692010000500018\&lng= en\&nrm=iso $>$. Acesso em 9 de Março de 2013. 